\title{
In situ localization of the secretion of lignin peroxidases in colonies of Phanerochaete chrysosporium using a sandwiched mode of culture
}

\author{
Serge M. Moukha, ${ }^{1 *}$ Han A. B. Wösten, ${ }^{2}$ Marcel Asther $^{1}$ and Joseph G. H. Wessels ${ }^{2}$ \\ ${ }^{1}$ Laboratoire de Biotechnologie des Champignons Filamenteux, INRA, Faculté des Sciences de Luminy, Parc \\ Scientifique et Technologique, 163 avenue de Luminy, Case Postale 929, F-13288 Marseille Cedex 09, France \\ ${ }^{2}$ Department of Plant Biology, University of Groningen, Kerklaan 30, NL-9751 NN Haren, The Netherlands
}

(Received 24 August 1992; revised 18 December 1992; accepted 4 January 1993)

\begin{abstract}
Protein secretion and growth were investigated in Phanerochaete chrysosporium by using cultures sandwiched between perforated polycarbonate membranes. Labelling of colonies with radioactive $N$-acetylglucosamine and Lmethionine indicated a close correlation between growth and general protein secretion, even in a central area of the colony secreting the idiophase enzymes lignin peroxidase (LiP) and manganese-dependent lignin peroxidase (MnP). Comparison of the sites of release into the medium of newly synthesized proteins and immuno-detected lignin peroxidases suggested that diffusion of the enzymes from the walls was a limiting step in the release of

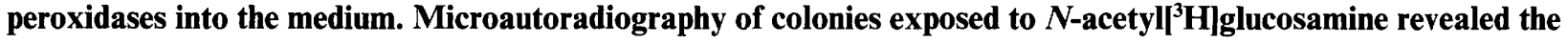
apical growth of thin hyphae and branches (4 to $5 \mu \mathrm{m}$ diameter on average) in the central secreting area. These secondary hyphae showed peroxidase activity and reacted with lignin peroxidase antibodies. Although it was not possible to directly visualize secretion at hyphal tips, the results suggest that peroxidases (LiP and MnP) are initially secreted at the apex of secondary growing hyphae and later slowly released into the surrounding medium.
\end{abstract}

\section{Introduction}

In liquid cultures of Phanerochaete chrysosporium, ligninolytic activity appears during the stationary phase after starvation for a nitrogen source (Kirk et al., 1978; Keyser et al., 1978) or, to a lesser extent, for a carbohydrate or sulphur source (Jeffries et al., 1981; Faison \& Kirk, 1985). Ligninolytic activity was found associated with multiple haemproteins with peroxidase activity (Tien \& Kirk, 1983; Glenn et al., 1983), i.e. lignin peroxidase isoenzymes (LiPs) (Kirk et al., 1986; Leisola et al., 1987) and manganese-dependent lignin peroxidase isoenzymes (MnPs) (Kuwahara et al., 1984; Glenn \& Gold, 1985; Leisola et al., 1987). Ligninolytic activity does not seem to be induced by the substrate (Keyser et al., 1978), although there are contradictory reports on this (Ulmer et al., 1984; Faison \& Kirk, 1985). In liquid cultures the major peroxidases excreted by $P$. chryso-

* Author for correspondence. Tel. 91416285 ; fax 91416707.

Abbreviations: BCIP, 5-bromo-4-chloro-3-indolyl phosphate; LiP, lignin peroxidase; $\mathrm{MnP}$, manganese-dependent lignin peroxidase; $\mathrm{LN}$, low-nitrogen minimal medium; HN, high-nitrogen minimal medium; PVDF, polyvinylidene difluoride. sporium were found to be $\mathrm{LiP}$ isoenzymes $\mathrm{H}_{2}$ and $\mathrm{H}_{8}$ (Kirk et al., 1986), but Bonnarme \& Jeffries (1990) showed that in the presence of a high manganese concentration the majority of excreted peroxidases are MnP isoenzymes. Similarly, Datta et al. (1991) found that in semi-solid-state cultures on aspen wood pulp, which contains a high concentration of $\mathrm{Mn}(\mathrm{II})$, the major peroxidase formed by $P$. chrysosporium was an isoenzyme of $\mathrm{MnP}$. Little is known about the regulation of the peroxidases ( $\mathrm{LiP}$ and $\mathrm{MnP}$ ) at the molecular level (Broda et al., 1989).

With respect to secretion, the cDNA sequences identified for lignin peroxidase LiP (Tien \& Tu, 1987; De Boer et al., 1987; Andrawis et al., 1989; Holzbaur et al., 1989; Ritch et al., 1991) or MnP (Pribnow et al., 1989; Pease et al., 1989) of $P$. chrysosporium predict the synthesis of preproteins with hydrophobic signal peptides. In addition, a LiP isoenzyme has been shown to be synthesized as a preproprotein (Ritch et al., 1991). Enhanced secretion of peroxidases was observed by adding phospholipids to the medium and was correlated with proliferation of endoplasmic reticulum and mitochondria as shown by the activities of marker enzymes (Capdevila et al., 1990). Enhancement of the secretion of peroxidases and proliferation of endoplasmic reticulum 
was also observed after addition of inositol (Moukha $e t$ al., 1991). Electron microscopic analyses of $P$. chrysosporium inoculated on wood have variously suggested the location of peroxidase enzymes ( $\mathrm{LiP}$ or $\mathrm{MnP}$ ) in the hyphal wall or slime layer (Daniel et al., 1989, 1990; Ruel \& Joseleau, 1991), in the periplasmic space (Forney et al., 1982; Srebotnic et al., 1988; Daniel et al., 1989, 1990) or in association with the plasma membrane and with membranes or lumina of cytoplasmic vesicles (Garcia $e t$ al., 1987; Srebotnic et al., 1988; Daniel et al., 1989, 1990). However, these studies, employing wood as a substrate, did not permit a satisfactory spatial and temporal overview of peroxidase secretion with respect to the whole mycelium. Also, they did not allow for a distinction between primary and secondary (idiophasic) growth as occurring in artificial media. We therefore attempted to localize both the secretion of peroxidases and the occurrence of hyphal growth in $P$. chrysosporium colonies using a cultivation method previously shown to be successful in localizing glucoamylase secretion in Aspergillus niger (Wösten et al., 1991). Our results suggest that peroxidases which are secreted in the centre of the colony after radial growth ceased are nevertheless secreted by growing hyphal branches and that there is a delay between the synthesis of these enzymes and their release into the medium.

\section{Methods}

Organism and culture media. Phanerochaete chrysosporium strain BKM-F-1767 (ATCC 24725) was used throughout. Cultures were grown on a medium derived from Capdevila et al. (1990) with the following changes: the medium was solidified with $15 \mathrm{~g}$ agar $\mathrm{l}^{-1}$, lipids and yeast extract were omitted but $10 \mathrm{~g}$ glucose $\mathrm{l}^{-1}$ was added as a carbon source and 10 mM-sodium acetate $\mathrm{pH} 4.5$ as a buffer. For highnitrogen minimal medium (HN) $1.8 \mathrm{~g} \mathrm{~L}$-asparagine $\mathrm{l}^{-1}(24 \mathrm{mM}-\mathrm{N})$ and for low-nitrogen minimal medium (LN) $0 \cdot 18 \mathrm{~g} \mathrm{~L}$-asparagine $1^{-1}(2 \cdot 4 \mathrm{~mm}$ N) was added.

Sandwiched cultures. A $2 \mathrm{~mm}$ diameter disc of mycelium from the edge of a 3-d-old colony was used to inoculate a thin $(0.3 \mathrm{~mm})$ layer of $1.25 \%(\mathrm{w} / \mathrm{v})$ agarose sandwiched between two perforated polycarbonate membranes $(7.6 \mathrm{~cm}$ diameter, standard pore size $0.08 \mu \mathrm{m}$, Poretics Corporation, Livermore, USA). The sandwich was placed centrally on $20 \mathrm{ml}$ minimal agar medium in a $9 \mathrm{~cm}$ Petri dish (for details see Wösten et al., 1991). This cultivation method allowed for rapid radiolabelling of proteins and hyphal walls, free diffusion of nutrients and secreted proteins, transfer of the colony without loss of hyphal orientation, and microscopic analysis of the nearly two-dimensional colony. In all cases the plates were incubated at $30^{\circ} \mathrm{C}$ in watersaturated air. Each experiment was done in triplicate and repeated at least twice. Standard deviations did not exceed $5 \%$ of the mean values.

Localization of secreted proteins at the level of the colony. For detection of secreted protein, a polyvinylidene difluoride (PVDF) membrane (Immobilon-P, Millipore, wetted with methanol and water according to the protocol of the manufacturer) was temporarily positioned between the bottom polycarbonate membrane and the agar medium. The PVDF membrane was then removed and cut into sectors as required. The membrane sectors were used for detection of secreted proteins by immunological or enzymic activity tests or by autoradiography after radioactive labelling.

Immunological detection of lignin peroxidases on PVDF membranes. Lignin peroxidases were detected on PVDF membranes using a rabbit antiserum raised against lignin peroxidase isoenzyme 9, pI 4.8 (Odier \& Delattre, 1990). Preimmune serum was obtained from the same rabbit before immunization. After SDS-PAGE of denatured proteins from a mycelium secreting peroxidase and Western blotting, the $1 / 50000$ diluted immune serum only reacted with bands around 42 and $46 \mathrm{kDa}$, corresponding to the molecular masses of the peroxidase (LiP and $\mathrm{MnP})$. However, in the range of the working serum dilution ( $1 / 1000$ to $1 / 3000$ ), the immune serum also cross-reacted with some other LiP isoenzymes as well as with $\mathrm{MnP}$ isoenzymes. Consequently, the antibodies raised against lignin peroxidase isoenzyme 9 could be used to detect peroxidase in general ( $\mathrm{LiP}$ and $\mathrm{MnP}$ ). All incubations were done at room temperature. The PVDF membrane was rewetted (see above) if necessary and equilibrated with phosphate-buffered saline, $\mathrm{pH} 7.2$ (PBS). Blocking was done for $2 \mathrm{~h}$ with PBS containing $0.02 \%$ sodium azide, $5 \%(\mathrm{w} / \mathrm{v})$ skimmed milk (Oxoid) and $1 \%(\mathrm{w} / \mathrm{v})$ polyvinyl pyrrolidone (PVP, $M_{\mathrm{r}} 40000$, Sigma), the latter preventing non-specific adsorption of anti-lignin peroxidase 9 antibodies to aromatic compounds (e.g. fungal pigments and Poly B-411 used for detection of lignin peroxidase activity). After removing excess blocking solution, the PVDF membranes were incubated with anti-lignin peroxidase serum, diluted $1 / 3000$ with $1 / 10$-strength blocking solution in PBS, for $1 \mathrm{~h}$. The membranes were washed twice with PBS for $5 \mathrm{~min}$ and additionally for $5 \mathrm{~min}$ with $1 / 10$-diluted blocking solution. Primary antibodies were detected by incubating for $1 \mathrm{~h}$ with alkalinephosphatase-conjugated goat anti-rabbit antibodies (Boehringer Mannheim), diluted $1 / 6000$ in $1 / 10$-strength blocking solution. The membranes were then washed three times for $5 \mathrm{~min}$ with PBS and colour developed by using the substrates nitroblue tetrazolium and BCIP (Boehringer Mannheim).

Localization of secreted peroxidase activity. To monitor the appearance of peroxidase activity in the medium, 0.02\% (w/v) Poly B-411 dye (Sigma) was added to the agar medium (Glenn \& Gold, 1983). When Poly B-411 was not included in the medium, peroxidase activity was detected by incubating PVDF membranes or agar medium for $20 \mathrm{~min}$ with $10 \mathrm{ml} 0.05 \%(\mathrm{w} / \mathrm{v})$ benzidine, $0.1 \%(\mathrm{w} / \mathrm{v})$ sodium nitroferricyanide (Mesulam, 1982) in $0.1 \mathrm{M}$-sodium acetate buffer pH 3.5, in the presence of $0.54 \mathrm{~mm}-\mathrm{H}_{2} \mathrm{O}_{2}$. In control experiments $\mathrm{H}_{2} \mathrm{O}_{2}$ was omitted. The reaction was terminated after $20 \mathrm{~min}$ by adding EDTA to a final concentration of $0.1 \mathrm{M}$.

Localization of general protein synthesis and secretion at the colony level. A piece of rice paper matching the diameter of the colony and soaked in a solution $\left(3 \mu \mathrm{cm}^{-2}\right)$ containing $65 \mathrm{kBq} \mu \mathrm{l}^{-1}$ of $\mathrm{L}$ $\left[{ }^{35} \mathrm{~S}\right]$ methionine (sp. act. $37 \times 10^{12} \mathrm{~Bq} \mathrm{mmol}^{-1}$, Amersham) was placed on the top polycarbonate membrane. After $30 \mathrm{~min}$ incubation, a PVDF membrane was placed between the bottom polycarbonate membrane of the sandwiched colony and the agar medium. After $1 \mathrm{~h}$ the colony was fixed with freshly prepared $4 \%$ (w/v) paraformaldehyde for $15 \mathrm{~min}$ and the polycarbonate membranes were removed. The agarose slab, containing the fixed colony, and the PVDF membrane, holding secreted proteins, were washed three times for $1 \mathrm{~h}$ with a solution containing $5 \mathrm{~mm}$ non-radioactive L-methionine. The agarose slab with the colony was dried overnight on filter paper and both the dried colony and the dried PVDF membrane were subjected to autoradiography. Subsequently, PVDF membranes could be rewetted and used for immunodetection of peroxidase (see above).

Localization of peroxidases at the hyphal level. Peroxidase activity was detected by treating unfixed colonies in agarose slabs directly with benzidine and $\mathrm{H}_{2} \mathrm{O}_{2}$ as described above for PVDF membranes. For 
immunolocalization of peroxidases, the colony was fixed in $4 \%(\mathrm{w} / \mathrm{v})$ paraformaldehyde for $20 \mathrm{~min}$. The polycarbonate membranes were removed and the agarose slab with the colony washed four times within $1 \mathrm{~h}$ with PBS. Sectors were incubated for $4 \mathrm{~h}$ in blocking buffer (see above) and then overnight at $4{ }^{\circ} \mathrm{C}$ with sera diluted $1 / 1600$ in blocking buffer but with $0.5 \mathrm{M}-\mathrm{NaCl}$ instead of $0.15 \mathrm{M}-\mathrm{NaCl}$ to prevent nonspecific binding to cell walls. The agarose slabs were washed four times with PBS and twice with $1 / 10$-strength blocking buffer containing $0.5 \mathrm{M}-\mathrm{NaCl}$. Detection of the primary antibodies was done by incubating for $2 \mathrm{~h}$ with gold-conjugated goat anti-rabbit antibodies ( $5 \mathrm{~nm}$ gold particles) in blocking buffer (with a final concentration of $0.5 \mathrm{M}-\mathrm{NaCl}$ ). After washing the slabs twice with PBS for $15 \mathrm{~min}$ and four times with double-distilled water for $15 \mathrm{~min}$, silver enhancement of the gold particles was done for $1 \mathrm{~min}$ according to the protocol supplied by the manufacturer of the reagent (Zymed Laboratories). Under these conditions self-nucleation of silver was not observed. As controls we used preimmune serum on colonies secreting lignin peroxidase and immune serum on colonies not secreting lignin peroxidase, i.e. young colonies grown on $\mathrm{LN}$ medium and 4-d-old colonies grown on $\mathrm{HN}$ medium.

Localization of growth. Growing apices were labelled for $10 \mathrm{~min}$ by placing on top of the sandwiched colony a rice paper soaked in a solution $\left(3 \mu \mathrm{cm}^{-2}\right)$ containing $3 \mathrm{kBq} \mu \mathrm{l}^{-1}$ of $N$-acetyl-D- $\left[1-{ }^{14} \mathrm{C}\right]$ glucosamine (sp. act. $2.2 \times 10^{9} \mathrm{~Bq} \mathrm{mmol}^{-1}$, Amersham) or $6.6 \mathrm{kBq} \mathrm{l}^{-1}$ of $N$-acetyl-D-[1,6- $\left.{ }^{3} \mathrm{H}\right]$ glucosamine (sp. act. $1.22 \times 10^{12} \mathrm{~Bq} \mathrm{mmol}^{-1}$, Amersham). After labelling, the colonies were fixed in $4 \%(w / v)$ paraformaldehyde for $15 \mathrm{~min}$ and washed three times for $1 \mathrm{~h}$ with a solution containing $0.44 \mathrm{~mm}$ non-labelled $\mathrm{N}$-acetyl-D-glucosamine. For macroautoradiography, ${ }^{14} \mathrm{C}$-labelled colonies in agarose slabs were dried overnight on a filter paper. For microautoradiography, pieces of ${ }^{3} \mathrm{H}$-labelled colonies were dried on glass slides coated with chromealum-gelatin.

Autoradiography. Macroautoradiography of ${ }^{14} \mathrm{C}$ - or ${ }^{35} \mathrm{~S}$-labelled colonies and PVDF membranes was done by using X-OMAT AR films (Eastman Kodak); colonies were exposed for $20 \mathrm{~min}$, membranes for $16 \mathrm{~h}$. Microautoradiography of ${ }^{3} \mathrm{H}$-labelled colonies was done by dipping glass slides mechanically (Rogers, 1969) in L4 emulsion (Ilford). After drying for $20 \mathrm{~min}$ in complete darkness, exposure was done in light-tight boxes containing silica gel for $3 \mathrm{~d}$ at $4{ }^{\circ} \mathrm{C}$. X-OMAT and L4 film were developed in Kodak D19 developer.

\section{Results and Discussion}

Phanerochaete chrysosporium was grown in sandwiched cultures on high and low nitrogen minimal media (HN and LN media) either containing or not containing $0.02 \%$ Poly B-411. Radial growth of the sandwiched colonies was similar to that of colonies directly inoculated on agar medium (Fig. 1). However, in the sandwiched colonies the upper polycarbonate filter ( $7.6 \mathrm{~cm}$ diameter) prevented formation of aerial hyphae. On LN medium the discoloration of Poly B-411 appeared in a homogeneous area in the centre of the colony between the third and the fourth day of growth, when the front of the colony had reached the edge of the Petri dish (confluence). This was seen on an underlying PVDF membrane, which adsorbed Poly B-411 from the agar medium (Fig. $2 c$, arrow). Colonies grown directly on agar medium showed a patchier discoloration of Poly B411 in the central area. For colonies grown on $\mathrm{HN}$, discoloration was faint and only visible between the seventh and the eighth day of growth (data not shown).

To correlate Poly B-411 discoloration with the presence of secreted peroxidases ( $\mathrm{LiP}$ and/or $\mathrm{MnP}$ ), a PVDF membrane was positioned under the bottom polycarbonate membrane at the time of inoculation. Immunodetection revealed the presence of lignin peroxidases on the PVDF membrane after $4 \mathrm{~d}$ growth, in the central area (Fig. $2 d$ ), i.e. roughly in the area where poly B-411 discoloration took place (Fig. $2 c, d$, arrows). No reaction was obtained with preimmune serum (Fig. $2 c$ ) or with a 3-d-old colony not yet discolouring Poly B-411 (Fig. 2b). The Poly B-411 discoloration front was always 2 to $4 \mathrm{~mm}$ ahead of the maximum immunodetected lignin peroxidases (Fig. $2 d$ ). This might indicate the presence of a more rapidly diffusing intermediate compound discolouring Poly B-411.

To correlate the immunodetected peroxidase with enzyme activity, the benzidine test was used. In this case Poly B-411 was not included in the medium. Similar secretion patterns were observed on PVDF sectors with both tests (Fig. $3 f, g$ ). No reaction was observed with the preimmune serum (Fig. $3 d, h$ ) or with the benzidine test in absence of $\mathrm{H}_{2} \mathrm{O}_{2}$ (Fig. $3 a, e$ ). However, in a few cases we noticed a faint benzidine reaction in the absence of $\mathrm{H}_{2} \mathrm{O}_{2}$, which might indicate the presence of phenol oxidases or traces of secreted $\mathrm{H}_{2} \mathrm{O}_{2}$ or MnP. No reactions were observed with PVDF underlying young colonies (Fig. $3 b, c$ ) or 4- and 5-d-old colonies grown on $\mathrm{HN}$ medium with the same tests (results not shown). There is thus a good correlation between the presence and activity of secreted peroxidases, revealing no inactive form of peroxidases or inactivation of peroxidases after secretion. These results also indicate that the presence of Poly B-

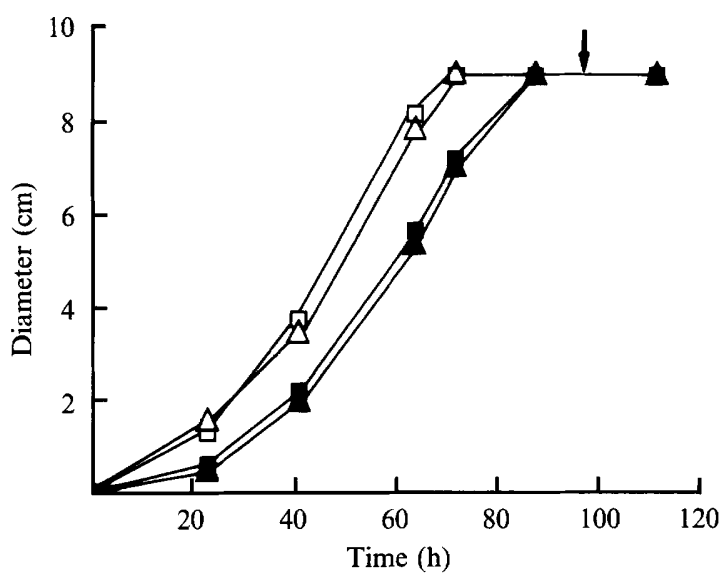

Fig. 1. Radial growth of $P$. chrysosporium directly grown on agar or sandwiched between two polycarbonate membranes. HN medium: $\triangle$, non-sandwiched; $\square$, sandwiched. LN medium: $\boldsymbol{\Delta}$, non-sandwiched; $\mathbf{\square}$, sandwiched. The arrow indicates the beginning of Poly B-411 dye discoloration. 

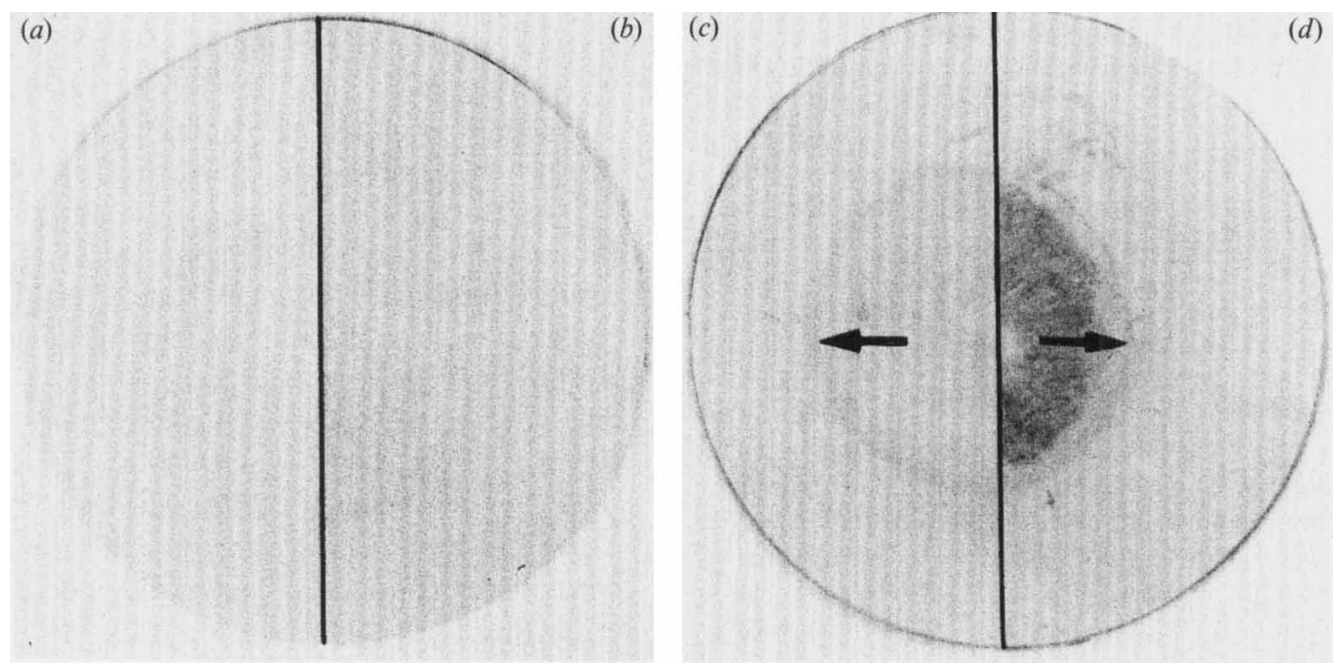

Fig. 2. Detection of lignin peroxidase on PVDF membranes underlying sandwiched colonies grown on LN medium in the presence of Poly B-411. $(a, b)$ 3-d-old colony not discolouring Poly B-411, $(c, d)$ 4-d-old colony discolouring Poly B-411 and secreting immunologically related peroxidases. $(a, c)$ Pre-immune serum; $(b, d)$ anti-LiP 9 serum visualizing the presence of lignin peroxidases. Arrows in $(c)$ and $(d)$ indicate the limit of discoloration of Poly B-411 on the membranes.
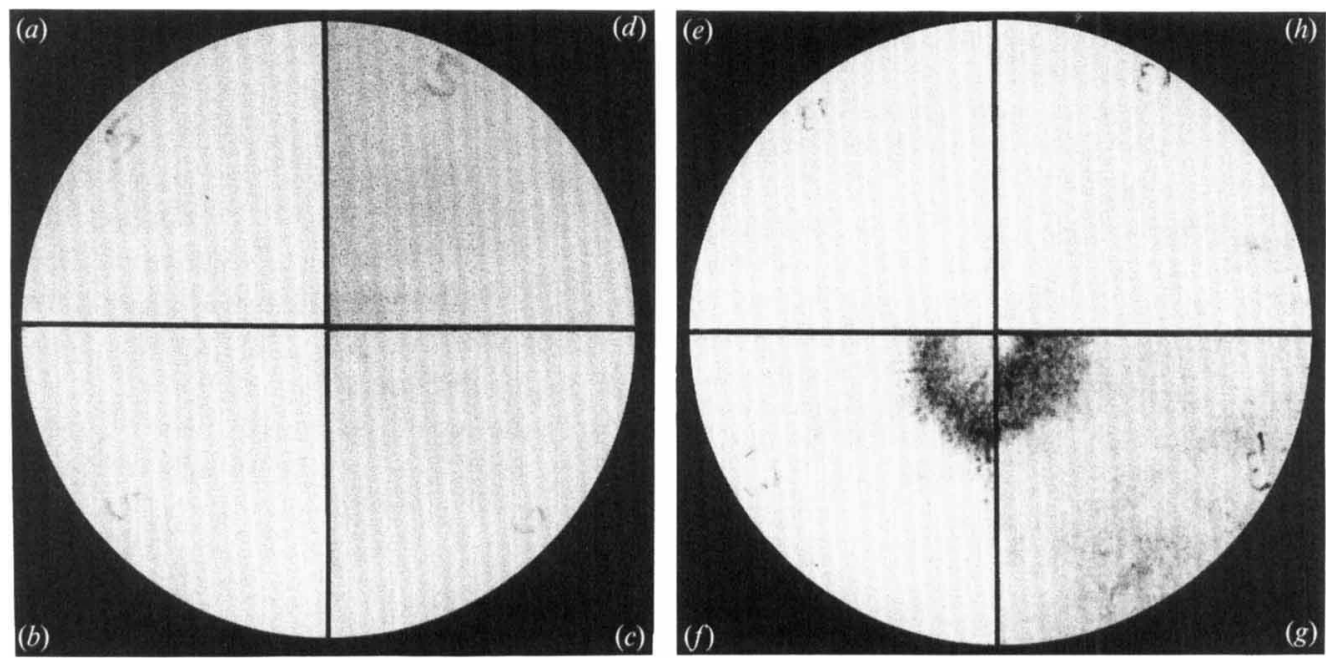

Fig. 3. Detection of lignin peroxidases on PVDF membranes underlying sandwiched colonies grown on LN medium in the absence of Poly B-411. ( $a-d)$ 3-d-old colony not secreting lignin peroxidases; $(e-h) 4$-d-old colony secreting lignin peroxidases. $(a, e)$ Reaction with benzidine in the absence of $\mathrm{H}_{2} \mathrm{O}_{2} ;(b, f)$ as $(a)$ but in the presence of $\mathrm{H}_{2} \mathrm{O}_{2} ;(c, g)$ reaction with anti-LiP 9 serum; $(d, h)$ as $(c)$ but with preimmune serum.

411 was not essential to induce a detectable amount of secreted peroxidases. Moreover, the presence of the dye had no influence on the pattern of secretion of peroxidases.

Hyphal growth in colonies was monitored by autoradiography after incorporation of labelled $\mathrm{N}$-acetylglucosamine into chitin. In 2- and 3-d-old colonies grown on LN medium, not yet producing peroxidase or discolouring Poly B-411, labelled $\mathrm{N}$-acetylglucosamine was essentially incorporated at the advancing front of the colonies only (Fig. $4 a, b$ ). In contrast, with colonies discolouring Poly B-411 (i.e. 4- or 5-d-old colonies), two zones incorporating $\mathrm{N}$-acetyl[ $\left[{ }^{14} \mathrm{C}\right]$ glucosamine could be distinguished in the central area (Fig. $4 c$ ). First, a narrow heavily labelled zone, coinciding with the outer limit of Poly B-411 discoloration (Fig. $4 c$, arrows). In this area, microautoradiography showed apical labelling of thin hyphae (see Fig. $6 a$, thin arrows). These secondary hyphae were 4 to $5 \mu \mathrm{m}$ in diameter on average, compared to the diameter of 7 to $8 \mu \mathrm{m}$ of non-labelled hyphae also 
(a)

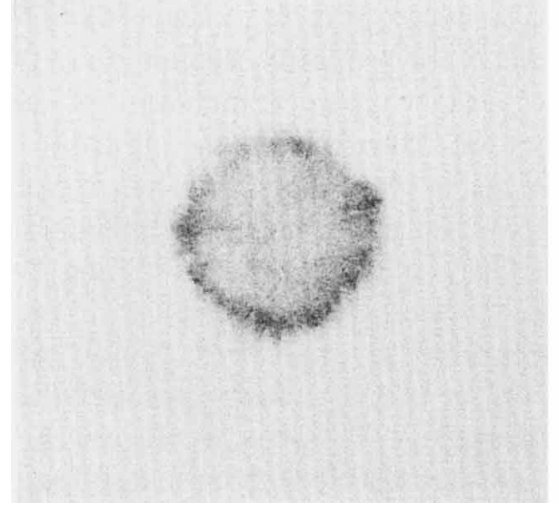

(b)

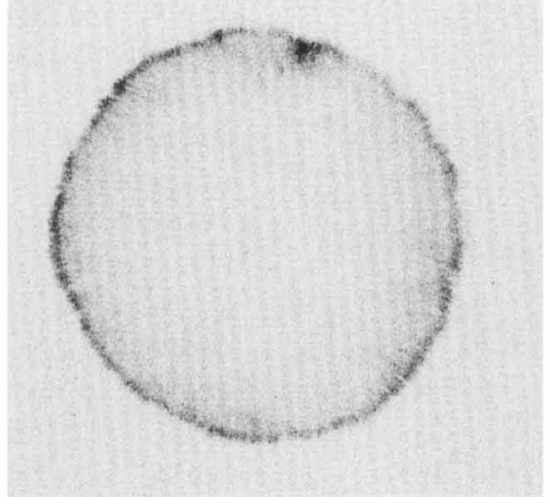

(c)

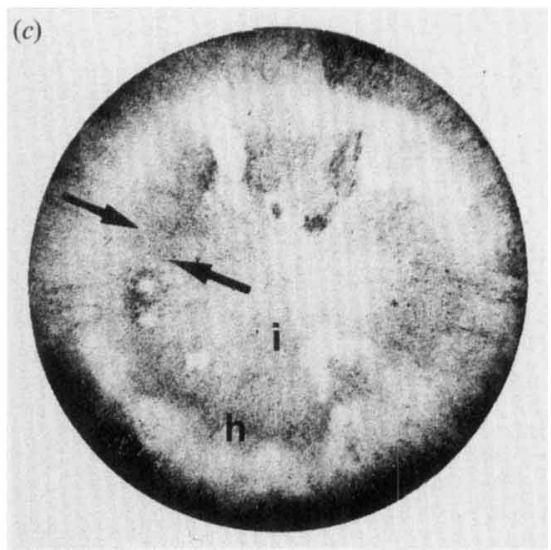

Fig. 4. Macroautoradiographs of sandwiched colonies after $10 \mathrm{~min}$ incorporation of $\mathrm{N}$-acetyl $\left[{ }^{14} \mathrm{C}\right]$ glucosamine into chitin. (a) 2-d-old colony; (b) 3-d-old colony; (c) 4-d-old confluent colony secreting lignin peroxidases; the arrows indicate the heavily labelled zone (h), matching the outer limit of the poly B-411 discoloration, surrounding a less heavily labelled inner zone (i).

seen in that zone (see Fig. $6 a$, thick arrows). Second, an inner zone (Fig. 4c) which was less labelled; microautoradiography of this area showed some apical labelling of poorly branched secondary hyphae (see Figs $6 c$ and $7 d$ ).

Sandwiched colonies were exposed to L- ${ }^{35}$ S $]$ methionine and then transferred to a new PVDF membrane (see Methods). Macroautoradiography of 2-d-old colonies revealed that most of the colony, including the central area, was active in protein synthesis (Fig. $5 a$ ). In 3-d-old colonies the colony margin was more distinctly labelled (Fig. 5e). However, autoradiograms of the PVDF membranes from 2- or 3-d-old colonies showed secretion of newly labelled protein mainly at the periphery of the colonies (Fig. $5 b, f$ ). In 2- to 3-d-old colonies no secreted peroxidases were detected (Fig. $5 c, g$ ). Autoradiograms of 4-d-old confluent colonies and PVDF membranes showed both protein synthesis and secretion occurring predominantly in the central area (Fig. $5 i, j$ ). However, newly labelled proteins were mainly secreted at the periphery of the labelled central area as detected in the colony. With 4-d-old colonies, the immunodetection on the PVDF membrane showed that most of the secreted peroxidase was more central (i.e. the inner zone of Fig. $5 j, k$, which parallels the inner zone of Fig. $4 c$ ) than the ring of newly synthesized proteins (i.e. the peripheral zone of Fig. $5 j, k$, which is congruent with the heavily labelled zone of Fig. $4 c$ ): compare Figs $5(j)$ and $5(k)$. Apparently, most of the secreted peroxidases had been synthesized before the label was added and was slowly released into the medium after the colony was transferred onto the new PVDF membrane.

The occurrence of growth (incorporation of $\mathrm{N}$ acetyl $\left[{ }^{3} \mathrm{H}\right]$ glucosamine) and the presence of peroxidases were studied at the microscopic level. Neither 2- to 3-d-old colonies grown on $\mathrm{LN}^{-}$medium nor 4-d-old colonies grown on $\mathrm{HN}$ medium revealed peroxidases associated with hyphae.

In 4-d-old colonies grown on LN medium, peroxidases were confined to the central area. In this area, the benzidine test showed two zones of secretion congruent with the two zones already described for the incorporation of $\mathrm{N}$-acetyl $\left[{ }^{14} \mathrm{C}\right]$ glucosamine (Fig. $4 \mathrm{c}$ ). In the peripheral zone, corresponding to the narrow heavily labelled zone with $N$-acetyl[ $\left.{ }^{14} \mathrm{C}\right]$ glucosamine (Fig. $4 \mathrm{c}$ ), the benzidine precipitate (Fig. $6 d$ ) and $N$-acetyl $\left[{ }^{3} \mathrm{H}\right]$ glucosamine (Fig. $6 a$ ) were mainly found associated with apices of secondary hyphal branches. In the inner zone, corresponding to the less labelled inner zone with $N$-acetyl $\left[{ }^{14} \mathrm{C}\right]$ glucosamine of Fig. $4(c)$, the benzidine precipitate was mainly formed in the medium (Fig. $6 f$; dark background), matching the pattern of secreted peroxidase on PVDF membranes (Fig. $5 k$ ). In this zone, the benzidine precipitate was also found associated with secondary hyphae (Fig. $6 f$; arrows) with $N$-acetyl $\left[{ }^{3} \mathrm{H}\right]$ glucosamine-labelled apices (Fig. $6 c$, thin arrows). The transition between the two zones is represented in Fig. 6(e) for the benzidine staining and in Fig. $6(b)$ for $\mathrm{N}$-acetyl $\left[{ }^{3} \mathrm{H}\right]$ glucosamine incorporation. It was not possible to obtain such pictures using the immunodetection procedure, possibly because of its lower sensitivity. Indeed, enzymes secreted into the medium rapidly diffused from the agarose slab (Fig. $5 k$ ). For the same reason it might be that the enzymes were loosely fixed in the agarose and were washed out during the immunodetection procedure.

At higher magnification, the benzidine reaction product in the peripheral zone was mainly found associated with the apices of hyphal branches (Fig. $7 b$ ), where the label seemed to be formed at the cell surface (Fig. $7 b$, arrows). Immunogold labelling revealed the presence of peroxidases in the same location (Figs $7 c, 8 a$ and $8 b$ ) 
(a)

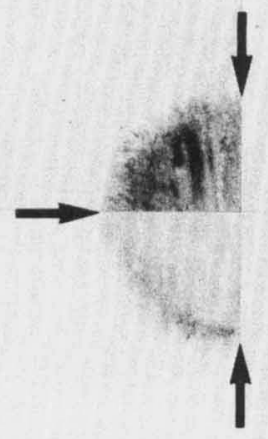

(b)

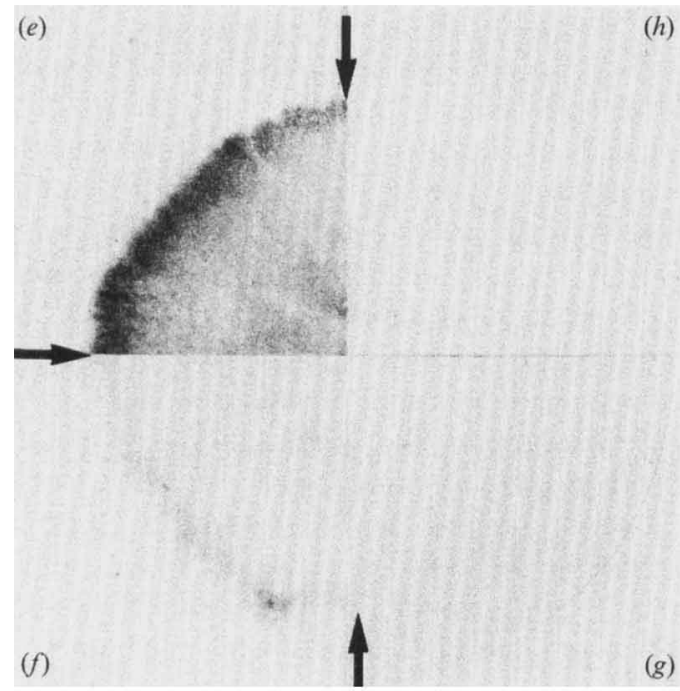

(i)

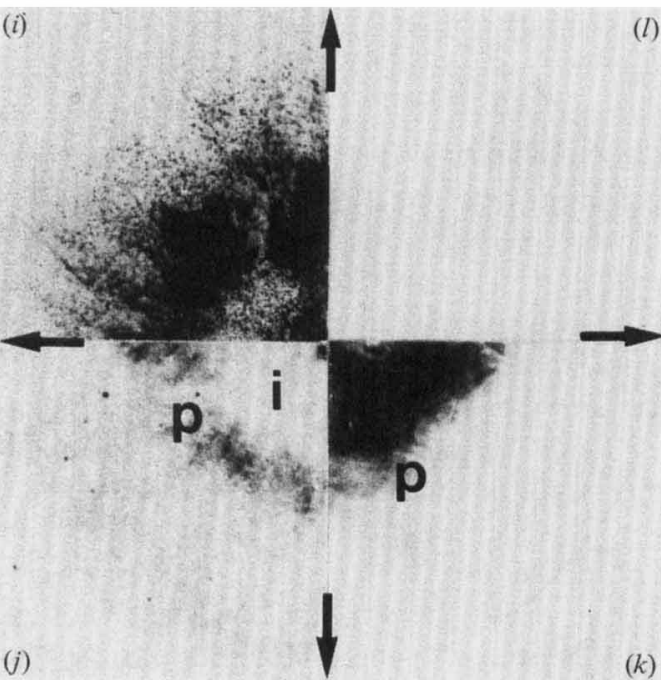

Fig. 5. Protein synthesis and secretion in sandwiched colonies grown on LN medium. $(a-d)$ A 2-d-old colony; $(e-h)$ a 3-d-old colony; $(i-l)$ a 4$\mathrm{d}$-old confluent colony secreting lignin peroxidases in the central area. while $\mathrm{N}$-acetyl $\left[{ }^{3} \mathrm{H}\right]$ glucosamine incorporation demonstrated the growth of these branches (Fig. 7a). This suggests that peroxidases are primarily secreted on to the cell surface of the secondary hyphal branches ( 4 to $5 \mu \mathrm{m}$ diameter on average) located in the advancing front of the central area. In the inner zone, where peroxidases were released (Fig. $5 k$ ) and where benzidine precipitate was mainly formed in the medium surrounding the hyphae (Fig. 6f), peroxidases were associated with long, poorly branched secondary hyphae (Fig. 7e). It was difficult to localize the benzidine staining precisely, i.e. intra- or extracellularly (Fig. 7e, arrows). However, a similar localization was observed with the anti-ligninperoxidase serum (Fig. $7 f$ ), indicating that the peroxidase was located at the outside of the hyphae. Many of the secondary hyphae in this zone containing peroxidase ( $\mathrm{LiP}$ and $\mathrm{MnP}$ ) were incorporating $\mathrm{N}$ acetyl[ $\left.{ }^{3} \mathrm{H}\right]$ glucosamine at their tips (Fig. $7 d$ ).

Clearly, peroxidases are produced during invasive growth of fungi in wood and aid in the degradation of lignocellulose (Daniel et al., 1989, 1990; Blanchette et al., 1989). A comparison between natural growth in wood and growth on rich artificial media is difficult. In the wood, the fungus probably grows under substrate limitation, and distinction, in space and time, between primary and secondary growth is difficult to make. On artificial media as used in laboratory studies, peroxidases are only formed after the primary growth phase is over and the fungus enters a state of starvation for nutrients (Faison \& Kirk, 1985). However, it appears that on such artificial media lignin peroxidases are also produced during the exponential growth phase if glycerol instead of glucose is used as a carbon source (Asther et al., 1988; Roch et al., 1989). In addition, Orth et al. (1991) have described a mutant of $P$. chrysosporium that secretes peroxidase during exponential growth on glucose medium.

In the present work we have investigated the time and location of peroxidase secretion in colonies of $P$. chrysosporium, using the sandwich culture technique (Wösten et al., 1991). The most significant observation was that the synthesis of peroxidases can be found closely associated with apical regions of hyphae, even though secretion of the enzymes only occurs after the growth of the colony as a whole has come to a halt. The enzymes are synthesized and secreted in the centre of the

$(a, e, i)$ Autoradiographs of colonies after labelling with ${ }_{\mathrm{L}-}\left[{ }^{35} \mathrm{~S}\right]-$ methionine, representing total mycelial protein synthesis; $(b, f, j)$ autoradiographs of PVDF membranes underlying the colonies, representing newly synthesized secreted proteins; $(c, g, k)$ secreted lignin peroxidases on PVDF membranes detected with anti-LiP 9 serum. $(d, h, l)$ As $(c)$ but reacted with pre-immune serum. Arrows indicate the outer edge of colonies. In $(j)$ and $(k)$ : p, peripheral zone; i, inner zone. 

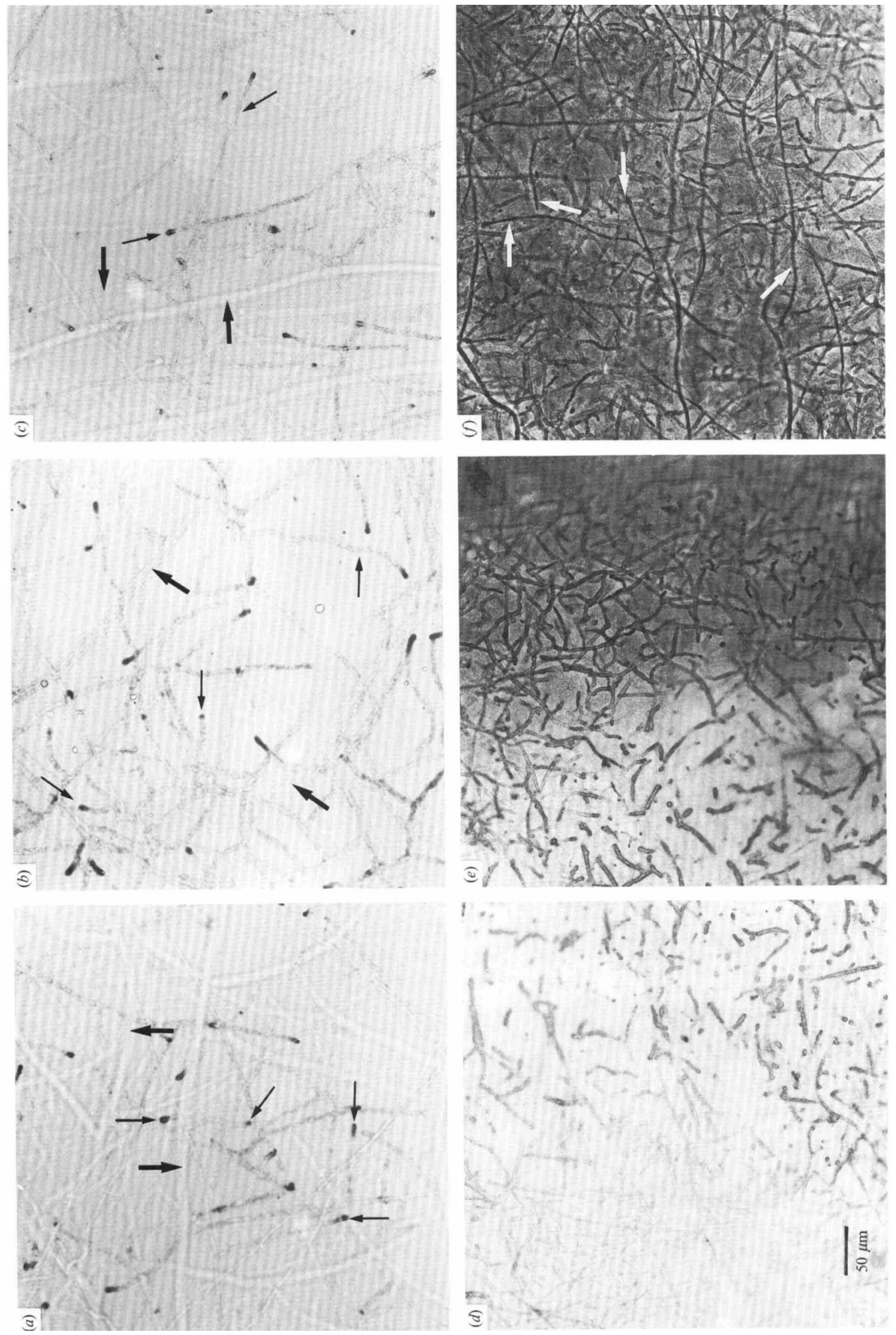

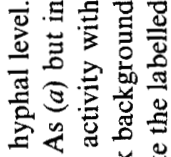
ङ 穴 âी 灵照额. के 뉼 8.9 돌 于 8 造啳

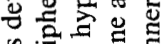

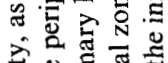

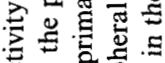
造诺范

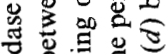

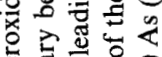
政

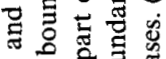

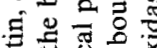
흥

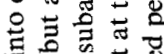
可吉

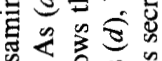

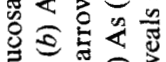

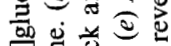

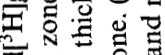

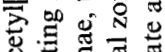
क्ष 之. 穴矛宫

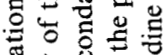

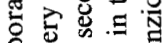
象品品 证 不

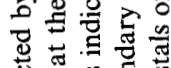
边记

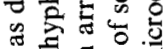

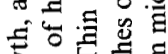
3.

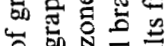

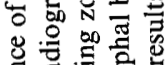
远 을 O

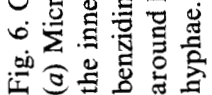



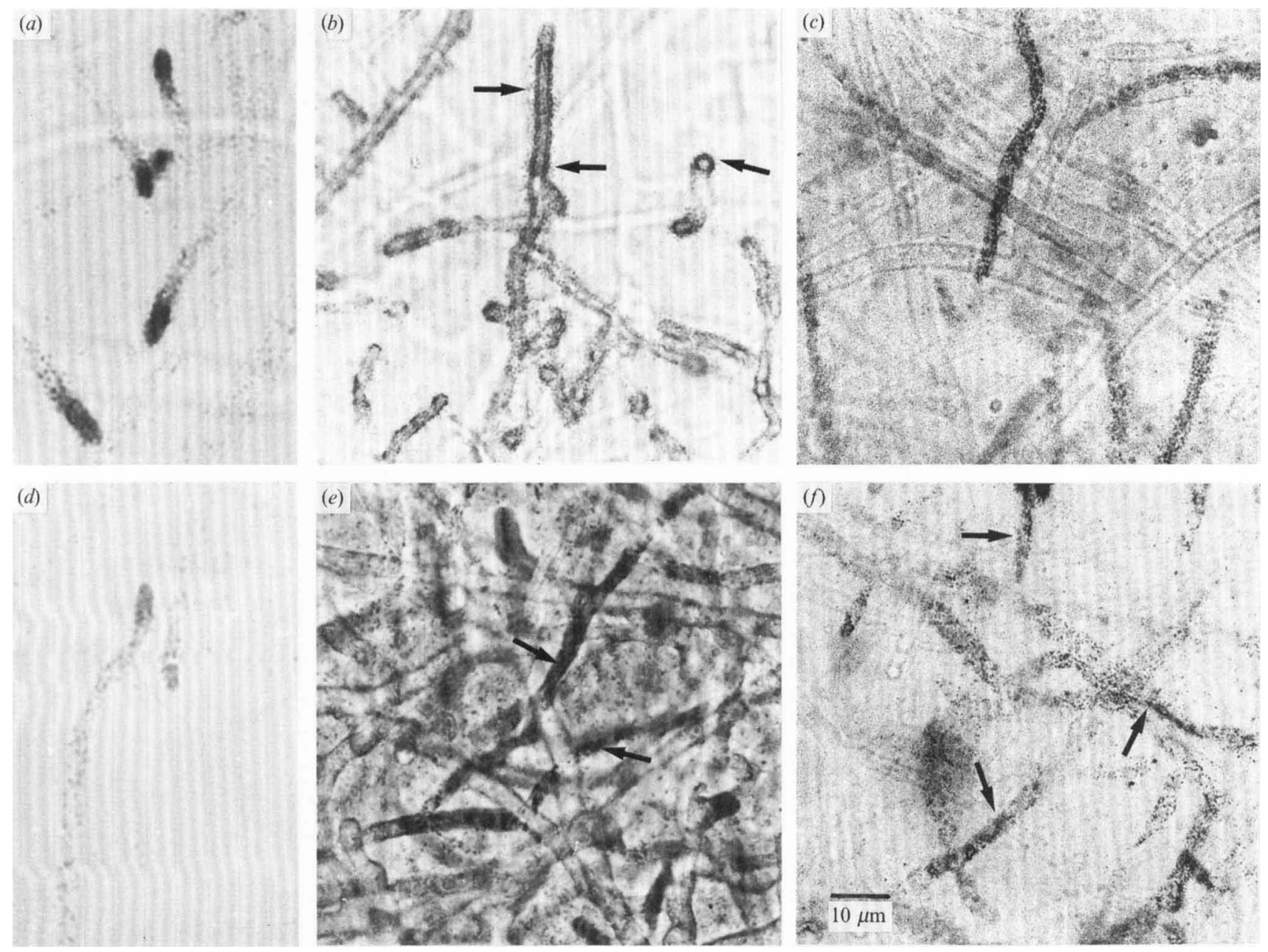

Fig. 7. Localization of growth by microautoradiography after labelling with $\mathrm{N}$-acetyl[ $\left.{ }^{3} \mathrm{H}\right] \mathrm{glucosamine}$ and of lignin peroxidases by benzidine oxidation and immunogold labelling at high magnification. $(a-c)$ Peripheral zone: $(a)$ Microautoradiography of hyphal branches; $(b)$ benzidine precipitate formed on the hyphal surface of branches (arrows); $(c)$ as $(b)$ but with immunogold labelling. ( $d-f$ ) Inner excreting zone: $(d)$ Microautoradiography of secondary hyphae; $(e)$ benzidine precipitate associated with secondary hyphae (arrows) and medium. $(f)$ lignin peroxidases revealed by immunogold labelling; arrows indicate labelled secondary hyphae.

colony by hyphae which resume growth by branching. Apparently, these hyphae grow by drawing upon metabolites produced during the primary growth phase. After radial growth of the colony has ceased, a front of branching hyphae moves from the centre of the colony outwards, correlated with the outward movement of the secretion zone.

At the time when peroxidases are secreted into the medium the benzidine reaction and especially the immunogold labelling of lignin peroxidases ( $\mathrm{MnP}$ and/or $\mathrm{LiP}$ ) is found over a long distance of the hyphae where the labelling seems to be more patchy (Fig. $7 f$ ). This suggests that enzymes are released from the hyphae into the surrounding medium and that this process is slow (see above, Fig. 5). In our experiments, the stage of maturity of the subapical cells of secondary hyphae was difficult to assess. Because of the label, i.e. benzidine precipitate or immunogold, no clear evidence for cell autolysis or cell wall hydrolysis of the secondary hyphae was obtained. However, the results of Lackner et al. (1991) indicate that lignin peroxidases are secreted by a cell autolytic process. Furthermore, they showed that immunoglobulin conjugated to $5 \mathrm{~nm}$ colloidal gold particles was able to label the lignin peroxidase-primary antibody complex intracellularly, suggesting the presence of large pores in the subapical walls allowing the passage of secreted enzymes.

Ruel \& Joselau (1991) found that peroxidases were secreted at the cell surface. They showed that hyphae of $P$. chrysosporium growing in wood were encapsulated by a glucan sheath (called mucilage) that accumulated principally at the hyphal apex. This glucan sheath appeared to be closely associated with hyphal cell wall surface. The lignin peroxidases were found in the glucan 


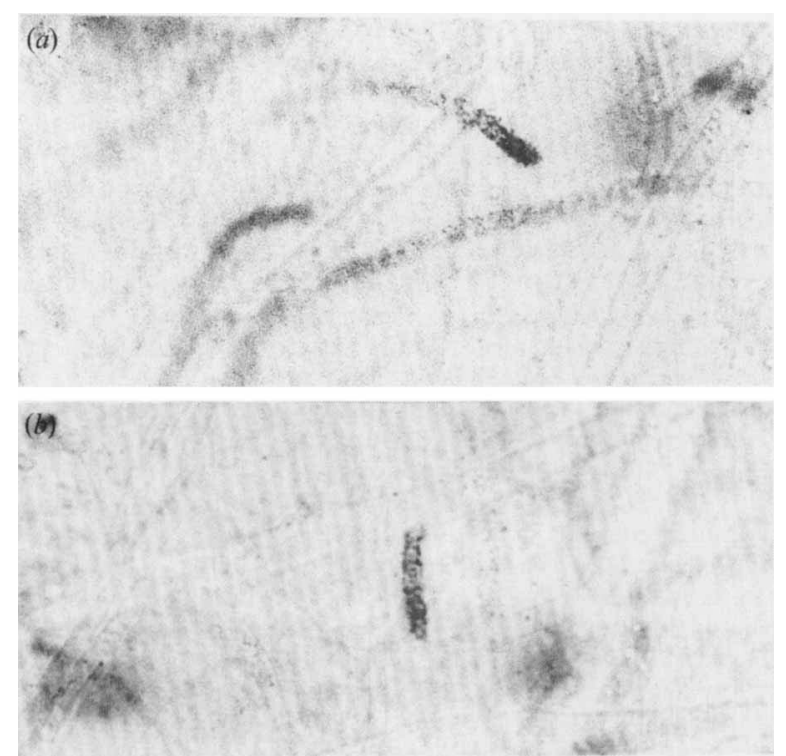

Fig. 8. Localization of the immunogold labelling as in Fig. 7(c), showing, in the peripheral zone: $(a)$ a labelled apex of a secondary hypha; $(b)$ an apically and subapically labelled branched secondary hypha. Magnification $\times 500$.

sheath; and in vitro, peroxidases extracted from extracellular fluid of fungal cultures had an affinity for this polymer. However, the sheath could be present around hyphae in which peroxidases remained intracellular or wall bound. Ruel \& Joselau (1991) concluded that the fungal cell wall must be sufficiently modified to allow the enzymes to be secreted. They also noted that the glucan sheath was hydrolysed during wood attack, demonstrating its active role in providing the $\mathrm{H}_{2} \mathrm{O}_{2}$ for peroxidase as well as providing a mode of transport of the fungal enzymes to their substrate at the surface of the wood cell wall.

In the present experiments, in the peripheral zone of the secreting zone we were unable to directly visualize, at the microscopic level (Figs $6 d$ and $7 b$ ), the secretion of the peroxidases from the apex into the medium. In the latter case, as previously mentioned, peroxidases were presumably associated with the cell surface at the apex (Figs $7 b$ and $8 a$ ) and subapically (Fig. 7b,c). The porosity of the cell wall was difficult to assess judging only from the aspect of the labelling. Therefore, in addition to the hypothesis that enzymes are synthesized and immediately secreted through pores in the subapical part of the hyphae, and taking into account that peroxidases might be associated with the cell surface, we cannot exclude the possibility that certain peroxidases (of the MnP or/and LiPs isoenzymes group) remained trapped transiently at the cell surface over a certain distance after being secreted at the apex of the growing hyphae. Indeed, there is cytological evidence that the secretory apparatus of filamentous fungi is located at the growing apex of hyphae (Grove, 1978). Usually, it is admitted that the sizes of pores in the mature subapical wall are too small to allow for passage of most excreted proteins (Trevithick \& Metzenberg, 1966; Money, 1990), and consequently the wall over the growing apex has been indicated as a major site for passage of proteins. One hypothesis proposed by Chang \& Trevithick (1974) is that the nascent wall at this site contains large pores. An alternative is offered by the 'bulk-flow' hypothesis (Wessels, 1990), which assumes that proteins excreted at the very tip are pushed through the wall to the outside of the wall by accretion of plastic wall polymers during apical wall growth. In either case protein excretion and apical wall growth should be tightly coupled. Such a coupling was previously found for excretion of glucoamylase in Aspergillus niger (Wösten et al., 1991).

S. M. Moukha is grateful to the EC for financial support to perform this work in the Netherlands as well as to Dr E. Odier and the INRA ligninase club in the initial phase of this research.

\section{References}

Andrawis, A., Pease, E. A., Kuan, I.-C., Holzbaur, E. \& Tien, M. (1989). Characterization of two lignin peroxidase cDNA clones from Phanerochaete chrysosporium. Biochemical and Biophysical Research communications 162, 673-680.

Asther, M., Lesage, L., Drapon, R., Corrieu, G. \& Odier, E. (1988). Phospholipid and fatty acid enrichment of Phanerochaete chrysosporium INA-12 in relation to ligninase production. Applied Microbiology and Biotechnology 27, 393-398.

Blanchette, R. A., Abad, A. R., Farrell, R. L. \& Leathers, T. D. (1989). Detection of lignin peroxidase and xylanase by immunocytochemical labeling in wood decayed by basidiomycetes. Applied and Environmental Microbiology 55, 1457-1465.

BonNARME, P. \& JefFries, T. W. (1990). Mn(II) regulation of lignin peroxidases and manganese-dependent peroxidases from lignindegrading white rot fungi. Applied and Environmental Microbiology 56, 210-217.

Broda, P., Sims, P. F. G. \& Mason, J. C. (1989). Lignin biodegradation: a molecular biological approach. Essays in Biochemistry 24, 82-114.

Capdevila, C., Moukha, S., Ghyczy, M., Theilleux, J., Gelie, B., Delattre, M., Corrieu, G. \& Asther, M. (1990). Characterization of peroxidase secretion and subcellular organization of Phanerochaete chrysosporium INA-12 in the presence of various soybean phospholipid fractions. Applied and Environmental Microbiology 56, 3811-3816.

Chang, P. L. Y. \& Trevithick, J. P. (1974). How important is secretion of oxoenzymes through apical cell walls of fungi? Archives of Microbiology 101, 281-293.

Daniel, G., Nilsson, T. \& Petterson, B. (1989). Intra- and extracellular localization of lignin peroxidase during the degradation of solid wood and wood fragments by Phanerochaete chrysosporium by using transmission electron microscopy and immuno-gold labelling. Applied and Environmental Microbiology 55, 871-881.

Daniel, G., Petterson, B., Nilsson, T. \& Volc, J. (1990). Use of immunogold cytochemistry to detect $\mathrm{Mn}$ (II)-dependent and lignin peroxidases in wood degraded by the white rot fungi Phanerochaete chrysosporium and Lentinula edodes. Canadian Journal of Botany 68 , 920-933.

Datta, A., Bettermann, A. \& Kirk, T. K. (1991). Identification of a specific manganese peroxidase among ligninolytic enzymes secreted by Phanerochaete chrysosporium during wood decay. Applied and Environmental Microbiology 57, 1453-1460. 
De Boer, H. A., Zhang, Y. Z., Collins, C. \& Reddy, C. A. (1987) Analysis of nucleotide sequences of two ligninase cDNAs from a white-rot filamentous fungus, Phanerochaete chrysosporium. Gene 60, 93-102.

FAISON, B. D. \& KIRK, T. K. (1985). Factors involved in the regulation of a ligninase activity in Phanerochaete chrysosporium. Applied and Environmental Microbiology 49, 299-304.

ForNey, L. J., RedDY, C. A. \& PANKRATZ, H. S. (1982). Ultrastructural localization of hydrogen peroxide production in ligninolytic Phanerochaete chrysosporium cells. Applied and Environmental Microbiology 44, 732-736.

Garcia, S., Latge, J.-P., Prevost, M.-C. \& Leisola, M. (1987). Wood degradation by white rot fungi: cytochemical studies using lignin peroxidase-immunoglobulin-gold complexes. Applied and Environmental Microbiology 53, 2384-2387.

GLENN, J. K. \& GolD, M. H. (1983). Decolorization of several polymeric dyes by the lignin-degrading basidiomycete Phanerochaete chrysosporium. Applied and Environmental Microbiology 45, 1741-1747.

GLENN, J. K. \& GoLD, M. H. (1985). Purification and characterization of an extracellular $\mathrm{Mn}$ (II)-dependent peroxidase from the lignindegrading basidiomycete, Phanerochaete chrysosporium. Archives of Biochemistry and Biophysics 242, 329-341.

Glenn, J. K., Morgan, M. A., Mayfield, M. B., Kuwahara, M. \& GolD, M. H. (1983). An extracellular $\mathrm{H}_{2} \mathrm{O}_{2}$-requiring enzyme preparation involved in lignin biodegradation by the white rot basidiomycete Phanerochaete chrysosporium. Biochemical and Biophysical Research Communications 114, 1077-1083.

Grove, S. N. (1978). The cytology of hyphal tip growth. In The Filamentous Fungi, 1st edn, vol. III, pp. 28-50. Edited by J. E. Smith \& D. R. Berry. London: Arnold.

Holzbaur, E. L. F., ANDrawis, A. \& Tien, M. (1989). Structure and regulation of a lignin peroxidase gene from Phanerochaete chrysosporium. Biochemical and Biophysical Research Communications 155, 626-633.

JefFries, T. W., ChoI, S. \& KIRK, T. K. (1981). Nutritional regulation of lignin degradation by Phanerochaete chrysosporium. Applied and Environmental Microbiology 42, 290-296.

Keyser, P., KiRK, T. K. \& ZeiKus, J. G. (1978). Ligninolytic enzyme system of Phanerochaete chrysosporium: synthesized in the absence of lignin in response to nitrogen starvation. Journal of Bacteriology 135, 790-797.

Kirk, T. K., Schutz, E., Connors, W. J., Lorenz, L. F. \& Zeikus, J. G. (1978). Influence of culture parameters on lignin metabolism by Phanerochaete chrysosporium. Archives of Microbiology 117, 277-285.

Kirk, T. K., Croan, S., Tien, M., Murtagh, K. E. \& Farrell, R. L. (1986). Production of multiple ligninases by Phanerochaete chrysosporium: effect of selected growth conditions and use of a mutant strain. Enzyme and Microbial Technology 8, 27-32.

Kuwahara, M., Glenn, J. K., Morgan, M. A. \& Gold, M. H. (1984). Separation and characterization of two extracellular $\mathrm{H}_{2} \mathrm{O}_{2^{-}}$ dependent oxidases from ligninolytic cultures of Phanerochaete chrysosporium. FEBS Letters 169, 247-250.

LACKNER, R., SREBotNiK, E. \& MESSNER, K. (1991). Immunogold-silver staining of extracellular ligninases secreted by Phanerochaete chrysosporium. Canadian Journal of Microbiology 37, 665-668.

Leisola, M. S. A., Kozulic, B., MeussdoerfFer, F. \& FieChter, A. (1987). Homology among multiple extracellular peroxidases from Phanerochaete chrysosporium. Journal of Biological Chemistry 262. 419-424.
Mesulam, M.-M. (1982). Principles of horseradish peroxidase neurohistochemistry and their applications for tracing neural pathways - axonal transport, enzyme histochemistry and light microscopic analysis. In Tracing Neural Connections with Horseradish Peroxidase, pp. 1-151. Edited by M.-M. Mesulam. London: Wiley.

MoNEY, N. P. (1990). Measurement of pore size in the hyphal cell wall of Achlya bisexualis. Experimental Mycology 14, 234-242.

Moukha, S., Capdevila, C., Lesage, L., Delattre, M., Marion, D., CORrIEU, G. \& AsTHER, M. (1991). Increased endoplasmic reticulum content of Phanerochaete chrysosporium INA-12 by inositol phospholipid precursor in relation to peroxidase excretion. Applied Microbiology and Biotechnology 36, 265-269.

Odier, E. \& DelatTre, M. (1990). Multiple lignin peroxidases of Phanerochaete chrysosporium INA-12. Enzyme and Microbial Technology 12, 447-452.

Orth, A. B., DenNY, M. \& Tien, M. (1991). Overproduction of lignindegrading enzymes by an isolate of Phanerochaete chrysosporium. Applied and Environmental Microbiology 57, 2591-2596.

Pease, E. A., Andrawis, A. \& Tien, M. (1989). Manganese dependent peroxidase from Phanerochaete chrysosporium. Journal of Biological Chemistry 264, 13531-13535.

Pribnow, D., Mayfield, M. B., Nipper, V. J., Brown, J. A. \& Gold, M. H. (1989). Characterization of cDNA encoding a manganese peroxidase, from the lignin-degrading basidiomycete Phanerochaete chrysosporium. Journal of Biological Chemistry 264, 5036-5040.

Ritch, T. G., NiPPER, V. J., AKileswaran, L., Smith, A. J., Pribnow, D. G. \& Gold, M. H. (1991). Lignin peroxidase from the basidiomycete Phanerochaete chrysosporium is synthesized as a preproenzyme. Gene 107, 119-126.

Roch, P., Buswell, J. A., CaIN, B. R. \& Odier, E. (1989). Lignin peroxidase production by strains of Phanerochaete chrysosporium grown on glycerol. Applied Microbiology and Biotechnology 31, 587-591.

ROGERS, A. W. (1969). Techniques of Autoradiography, 3rd edn. Amsterdam/New York/Oxford: Elsevier/North-Holland Biomedical Press.

Ruel, K. \& JoseleaU, J.-P. (1991). Involvement of an extracellular glucan sheath during degradation of Populus wood by Phanerochaete chrysosporium. Applied and Environmental Microbiology 57, 374-384.

Srebotnik, E., Messner, K., Foisner, R. \& Petterson, B. (1988). Ultrastructural localization of ligninase of Phanerochaete chrysosporium by immunogold labeling. Current Microbiology 16, 221-227.

TIEN, M. \& KIRK, T. K. (1983). Lignin-degrading enzyme from the hymenomycete Phanerochaete chrysosporium Burds. Science 221, 661-663.

TIEN, M. \& Tu, C. P. D. (1987). Cloning and sequencing of a cDNA for a ligninase from Phanerochaete chrysosporium. Nature, London 326, $520-523$.

Trevithick, J. R. \& METZENBerG, R. L. (1966). Genetic alteration of pore size and other properties of the Neurospora cell wall. Journal of Bacteriology 92, 1016-1020.

Ulmer, D. C., Leisola, M. S. A. \& Fiechter, A. (1984). Possible induction of the ligninolytic system of Phanerochaete chrysosporium. Journal of Biotechnology 1, 13-14.

Wessels, J. G. H. (1990). Role of cell architecture in fungal tip growth generation. In Tip Growth in Plant and Fungal Walls, pp. 1-29. Edited by I. B. Heath. San Diego: Academic Press.

Wösten, H. A. B., Moukha, S. M., Sietsma, J. H. \& Wessels, J. G. H. (1991). Localization of growth and secretion of proteins in Aspergillus niger. Journal of General Microbiology 137, 2017-2023. 